\title{
Morning pulse of prolactin maintains seasonal quiescence in the tammar, Macropus eugenii
}

\author{
L. A. Hinds \\ CSIRO Division of Wildlife and Ecology, P.O. Box 84, Lyneham, A.C.T. 2602, Australia
}

\begin{abstract}
Summary. The pulse of prolactin, present in female tammars kept in an inhibitory photoperiod and absent 5 days after a change to a stimulatory photoperiod, was artificially maintained during stimulatory photoperiods (Exps $1 \mathrm{~A}$ and 1B) or abolished during an inhibitory photoperiod (Exp. 2). In Exp. 1A, thyrotrophin-releasing hormone (TRH) was injected i.v. for 8 consecutive mornings and in Exp. 1B ovine prolactin was injected i.v. for 10 consecutive mornings beginning on the day the photoperiod was changed from 15L:9D to 12L:12D. In Exp. 1A, in 5 of 6 control females the prolactin pulse was present until the 3rd morning after the lighting was changed, and absent thereafter. In both experiments the early progesterone peak and the interval to birth in the treated females was significantly delayed compared to the control females; reactivation of the $C L$ did not occur until treatment ceased.

In Exp. 2, for 5 consecutive mornings, before the prolactin pulse was expected to occur, bromocriptine was injected i.m. In $2 / 4$ treated animals the prolactin pulse was abolished and these animals showed an early progesterone peak and gave birth 28 and 29 days after treatment began. The remaining 2 animals and the controls $(N=4)$ did not show reactivation until after they experienced a stimulatory photoperiod.

The results indicate that the prolactin pulse is the critical factor in the maintenance of the inhibition of the $\mathrm{CL}$ of the tammar during seasonal quiescence.
\end{abstract}

Keywords: prolactin; corpus luteum; tammar; embryo; photoperiod; progesterone; bromocriptine

\section{Introduction}

The annual reproductive cycles of the tammar wallaby, Macropus eugenii, and Bennett's wallaby, Macropus rufogriseus rufogriseus, are characterized by two periods of quiescence, during which the corpus luteum (CL) is inhibited; in lactational quiescence the sucking stimulus of the pouch young maintains the inhibition, while in seasonal quiescence photoperiod is the proximate factor (Merchant \& Calaby, 1981; Tyndale-Biscoe et al., 1986; Loudon \& Curlewis, 1987; Tyndale-Biscoe \& Renfree, 1987, for review). In the tammar, the pituitary tonically inhibits the CL because hypophysectomy during either period of quiescence induces reactivation of the CL (Hearn, 1974). The inhibitory agent from the pituitary is prolactin because treatment with prolactin, either after removal of pouch young or after hypophysectomy, delays reactivation (Tyndale-Biscoe \& Hawkins, 1977), while injection of bromocriptine, which inhibits the release of prolactin in eutherian mammals, induces reactivation of the CL (Tyndale-Biscoe \& Hinds, 1984; TyndaleBiscoe et al., 1986; Curlewis et al., 1986).

When reactivation of the $C L$ is induced by removal of the pouch young, a peak of progesterone occurs at Day 5 or 6 and is followed 21-22 days later by birth (Hinds \& Tyndale-Biscoe, 1982a). Sadleir \& Tyndale-Biscoe (1977) found that tammars subjected to an artificial photoperiod of $15 \mathrm{~h}$ light:9 h dark (15L:9D) remained in quiescence until the photoperiod was changed to $12 \mathrm{~L}: 12 \mathrm{D}$. Births then occurred about 33-34 days later, 6 days longer than the interval to birth after the 
removal of pouch young (26-27 days; Merchant, 1979). However, the early progesterone peak occurred around Day 10 after the photoperiod change (Hinds \& den Ottolander, 1983). Subsequent studies have shown that the longer interval to birth after altered photoperiod is due to the time taken for a change in the duration of elevated melatonin concentration to be read by the brain and transmitted via the pituitary to the ovaries (McConnell \& Tyndale-Biscoe, 1985; McConnell et al., 1986; Tyndale-Biscoe et al., 1986).

In tammars kept in a summer solsticial photoperiod of $15 \mathrm{~L}: 9 \mathrm{D}$ there is a morning pulse of plasma prolactin which is absent 5 days after a change to a photoperiod of $12 \mathrm{~L}: 12 \mathrm{D}$. The pulse, which is coincident with lights on in the morning, is of $1-2 \mathrm{~h}$ duration and has a magnitude ranging from 30 to $100 \mathrm{ng} / \mathrm{ml}$ (McConnell et al., 1986). A similar pulse has not been described for Bennett's wallabies, although daily treatment with a single intramuscular injection of prolactin delayed reactivation in animals that had been exposed to a stimulatory light change (Brinklow \& Loudon, 1989).

The aim of this study was to investigate the role of the morning prolactin pulse in the maintenance of seasonal quiescence of the $\mathrm{CL}$ of the tammar.

\section{Materials and Methods}

\section{Animals and experimental design}

Adult female tammars $(4 \cdot 2-6 \cdot 3 \mathrm{~kg}$ ) were taken from the captive colony established from Kangaroo Island stock in 1974 and maintained at the CSIRO Divison of Wildlife and Ecology, Canberra. All experiments were conducted in light-proof rooms in which photoperiod was controlled; groups of 4 females were held in individual pens $(3.5 \mathrm{~m} \times 1.0 \mathrm{~m})$ and fed pelleted lucerne and oats, bread, cabbage and apples, and water ad libitum.

Two approaches were taken to maintain or to abolish the prolactin pulse, and thereby extend or decrease the period of inhibition of the CL. Intravenous injection of thyrotrophin releasing hormone (TRH) stimulates the release of endogenous prolactin (Hinds \& Tyndale-Biscoe, 1982b). Therefore in Exp. 1 the prolactin pulse was maintained artificially in females experiencing a stimulatory photoperiod, either by daily intravenous TRH injections (Exp. 1A), or daily intravenous injections of ovine prolactin (Exp. 1B). In Exp. 2 bromocriptine was administered in an attempt to inhibit the release of the prolactin pulse from the pituitary in females kept in an inhibitory photoperiod (see Fig. 1).

\section{Experiment 1: effect of maintaining the prolactin pulse in animals kept in a stimulatory photoperiod}

Experiment 1A. On 21 October, 12 non-lactating females were placed in a photoregimen of 18L:6D (lights off at 03:00 $\mathrm{h}$ and on at 09:00 h) (Fig. 1). After 14 days the lighting was changed to 12L:12D (lights off at 21:00 h and lights on at $09: 00 \mathrm{~h}$ ) and for the next 8 mornings, at $09: 30 \mathrm{~h}$, the animals received intravenous injections of $1.0 \mathrm{ml}$ phosphate-buffered saline (PBS) $(\mathrm{N}=6)$ or $40 \mu \mathrm{g}$ TRH (see below) in PBS $(\mathrm{N}=6)$. At 25 days after the light change males were introduced into the pens and daily checks for birth and/or oestrus (determined by the presence of a copulatory plug in the urogenital sinus) began.

Experiment $I B$. During lactational quiescence, the $C L$ of tammars held in a summer solsticial photoperiod for 2 weeks become inhibited and do not reactivate after removal of pouch young (L. A. Hinds \& C. H. Tyndale-Biscoe, unpublished observations). Therefore, on 27 March, 9 lactating females were placed in a photoregimen of 15L:9D (lights off at 22:00 h and on at 07:00 h) (Fig. 1). After 2 weeks their pouch young were removed and 19 days later the lighting was changed to $12 \mathrm{~L}: 12 \mathrm{D}$ (lights off at 19:00 h and on at 07:00 h). For the next 10 mornings, at 07:00 h, females received an intravenous injection of $50 \mu \mathrm{g}$ ovine prolactin (see below) in $0.5 \mathrm{ml}$ PBS $(\mathrm{N}=5)$ or $0.5 \mathrm{ml}$ PBS $(\mathrm{N}=4)$. Males were introduced into the pens on Day 22 and daily checks for births or oestrus began on Day 26 after the light change.

\section{Experiment 2: effect of abolishing the prolactin pulse in animals kept in an inhibitory photoperiod}

Eight non-lactating females were placed in an inhibitory photoperiod of $15 \mathrm{~L}: 9 \mathrm{D}$ (lights off at $22: 00 \mathrm{~h}$ and on at 07:00 h) on 10 August (Fig. 1). Beginning on 22 September (Day 0) and continuing until 26 September, females were treated with intramuscular injections of bromocriptine $(5 \mathrm{mg} / \mathrm{kg}$; Sandoz Australia, Pty Ltd, Sydney, Australia) or saline vehicle at $06: 00 \mathrm{~h}$, about $1 \mathrm{~h}$ before the prolactin pulse would occur naturally. At 14 days after the start of bromocriptine or saline treatment the photoregimen was changed to 12L:12D (lights off at 19:00 h and on at 07:00 h), so that any females which had not responded already would do so. On Day 22 all animals were removed to outside yards and males were introduced. Daily checks for births and/or oestrus began on Day 24. 

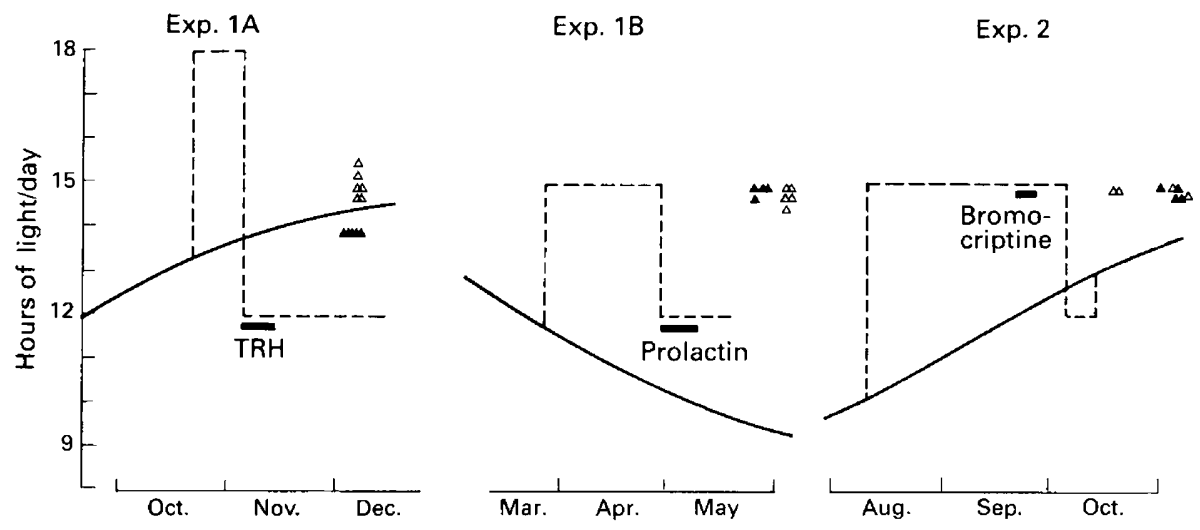

Fig. 1. Summary of the design and results for Exps $1 \mathrm{~A}, 1 \mathrm{~B}$ and 2 . The solid line represents natural light at $37 \cdot 5^{\circ} \mathrm{S}$. Broken lines represent the artificial light regimen experienced by the tammars in the light proof rooms. The horizontal bars indicate the period of treatment with TRH, prolactin or bromocriptine in the respective experiments. Closed arrows $=$ births/ oestrus in control females; open arrows $=$ births/oestrus in treated females.

\section{Collection of blood samples}

In Exp. 1A, samples for prolactin ( $1.0 \mathrm{ml})$ were collected on Days $-6,0$ to 4,7 and 8 after the change of photoregimen to monitor the presence of the early morning pulse of prolactin and the response to injection of TRH. On each of the above days samples were taken at the following times with respect to the time of lights on at 09:00 h; $-1,0,0 \cdot 5,1$ and $2 \mathrm{~h}$. TRH or PBS was administered intravenously immediately after collection of the blood sample at $0.5 \mathrm{~h}$.

In Exp. 1 B, samples for prolactin were taken only on the last day of injections (Day 9) at - 1, 0, 0.5, 1, 1.5, 2, 2.5 and $3 \mathrm{~h}$ after lights on. Ovine prolactin or PBS were administered intravenously immediately after the collection of the blood sample at $0 \mathrm{~h}$.

In Exp. 2, samples for prolactin were taken $-3,0,4$ and 8 days after the start of treatment at the same intervals refative to lights on as in Exp. 1B.

In Exp. 1, daily blood samples for analysis of progesterone $(2.8 \mathrm{ml})$ were collected from Days 4 to 15 after start of treatment for the control groups and from Days 4 to 18 (Exp. 1A) or 4 to 21 (Exp. 1B) for the treated groups for analysis of progesterone. In Exp. 2, samples were taken daily from the beginning of treatment with bromocriptine/saline (Days 0-10) and again after the lights were changed (Days 18-27).

All blood samples were placed on ice immediately after collection and separated by centrifugation within $1 \mathrm{~h}$. Aliquants of plasma were stored at $-15^{\circ} \mathrm{C}$ for subsequent assay of progesterone or prolactin.

\section{Preparations}

$T R H$. TRH (Sigma, St Louis, MO, USA), received as a lyophilized powder, was dissolved in sterile PBS, pH 7.0, at a concentration of $40 \mu \mathrm{g} / \mathrm{ml}$. TRH-treated females received $40 \mu \mathrm{g}(1.0 \mathrm{ml})$ intravenously and control females received $1.0 \mathrm{ml}$ PBS intravenously.

Ovine prolactin. Whole sheep pituitaries were collected from the Canberra abattoir and stored frozen until extraction. A crude prolactin fraction was prepared using a series of ammonium sulphate extractions as described by Neill \& Reichert (1971). Further purification was carried out by gel filtration on a Sephadex G100 column $(2.5 \times 100 \mathrm{~cm})$. After dialysis and lyophilization the fraction was stored in a dessicator at $4^{\circ} \mathrm{C}$. Purity of the fraction was confirmed by gel acrylamide electrophoresis and relative potency assessed using a mammary gland radioreceptor assay (Stewart, 1984). Relative to ovine prolactin NIH-P-S12, this preparation was approximately 4 times more potent.

Prolactin for injection. A stock solution ( $2 \mathrm{mg}$ ovine prolactin/ml) was prepared in PBS (pH 7.4) and diluted 1:20 to give $100 \mu \mathrm{g} / \mathrm{ml}$. Ten aliquants were frozen and each morning one of these was thawed just before injection. Each animal received $50 \mu \mathrm{g}$ in $0.5 \mathrm{ml}$.

Bromocriptine. Equal quantities of bromocriptine and D,L-tartaric acid were dissolved in 1 volume of $70 \%$ ethanol, before an equal volume of $0.9 \%(\mathrm{w} / \mathrm{v})$ sterile $\mathrm{NaCl}$ was added to give a final bromocriptine concentration of $25 \mathrm{mg} / \mathrm{ml}$. Treated animals received $5 \mathrm{mg}$ bromocriptine $/ \mathrm{kg}$ body weight $(=0.2 \mathrm{ml}$ solution $/ \mathrm{kg})$. Control animals received saline vehicle at the rate of $0.2 \mathrm{ml} / \mathrm{kg}$. This vehicle contained only tartaric acid dissolved in equal volumes of $70 \%$ ethanol and $0.9 \%$ sterile saline. 


\section{Hormone assays}

All the samples from the same experiment were analysed in the same assay. Progesterone in the plasma was determined by the radioimmunoassay described by Sernia et al. (1980) using antiserum 334 received as a gift from $\mathrm{Dr}$ R. I. Cox (CSIRO, Sydney, Australia). The sensitivity of the assay is $25 \mathrm{pg} / \mathrm{ml}$ and intra- and inter-assay coefficients of variation are 9 and $13 \%$ respectively.

Plasma prolactin concentrations were determined by the heterologous radioimmunoassay described by Hinds \& Tyndale-Biscoe (1982b) using antiserum 33/1-8 (a gift from Dr A. S. McNeilly, Edinburgh, UK) and ovine prolactin (NIH-P-S 12 ) as standard. The assay is sensitive to $2 \mathrm{ng} / \mathrm{ml}$ and intra- and inter-assay coefficients of variation are 8 and $12 \%$ respectively.

An endogenous pulse of prolactin was defined as a 2 -fold, or greater, increase in plasma prolactin in the samples collected before, coincident with or after lights on.

\section{Results}

Experiment 1: effect of maintaining the prolactin pulse in animals held on a stimulatory photoperiod

Experiment $1 A$ : response to TRH. TRH treatment induced an increase in plasma prolactin concentrations within $30 \mathrm{~min}$ on each of the days sampled. The response was maximal on the first
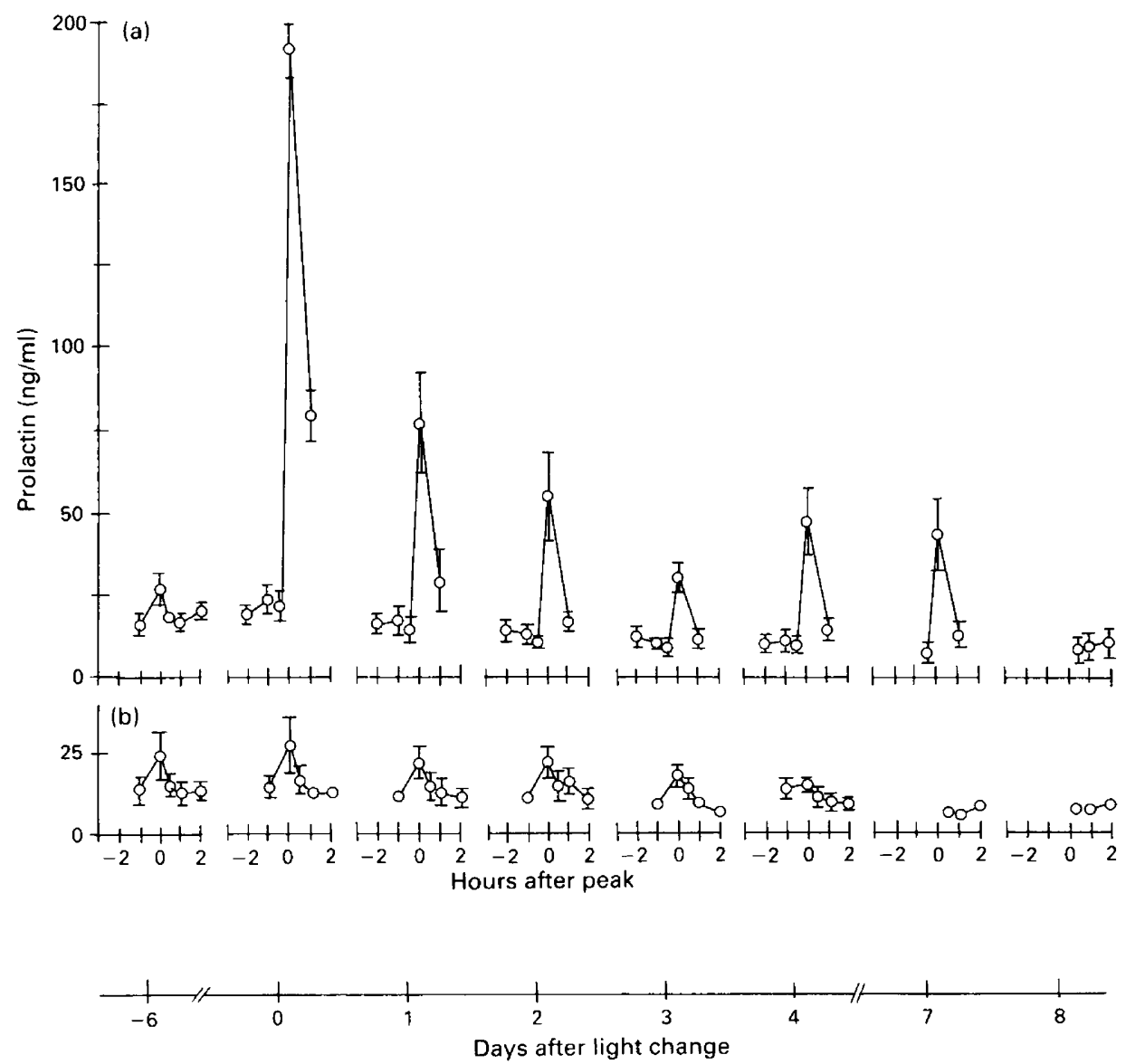

Fig. 2. Plasma prolactin concentrations (mean \pm s.e.m.) in tammars in Exp. 1A before and after daily intravenous treatment with (a) $40 \mu \mathrm{g}$ TRH $(\mathrm{N}=6)$ or (b) $1.0 \mathrm{ml}$ PBS $(\mathrm{N}=6)$. Treatment was given $30 \mathrm{~min}$ after lights on $(09: 30 \mathrm{~h}$ ) for 8 consecutive days (Days $0-7$ ) after the lighting was changed from $15 \mathrm{~L}: 9 \mathrm{D}$ to $12 \mathrm{~L}: 12 \mathrm{D}$. All results are aligned to the pulse prolactin value; i.e. in (a) the TRH-induced pulse and in (b) the endogenous prolactin pulse. 
day of treatment (Day 0), when the increase from basal levels was 10-fold, but thereafter it was less than 5-fold, with a minimum response on Day 3 after the light change (4th day of injection) (Fig. 2a). The response on Day 3 was of the same order of magnitude as the endogenous morning prolactin pulse.

Saline-treated animals showed morning prolactin pulses which ranged in magnitude from 12 to $55 \mathrm{ng} / \mathrm{ml}$. Because individual animals had their pulses at different times, i.e. before, coincident with or after lights on, the results have been aligned to the pulse (Fig. 2b). By Day 4 after the light change only one of the control animals showed a pulse. None had a pulse on Day 7 or 8 , by which time basal concentrations also were lower than on Day -6 . The magnitude of the naturally occurring pulses was not as great as those induced in the treated group on the first 3 days of TRH injection.

All control females showed early peaks of progesterone between Days 5 and 10 (Fig. 3); 4 gave birth and 1 came into oestrus 30-34 days after the change to 12L:12D (Fig. 3, Table 1). These responses are similar to those previously reported (Sadleir \& Tyndale-Biscoe, 1977; Hinds \& den Ottolander, 1983). The 6th female did not give birth and oestrus was not detected. The TRHtreated females all showed early peaks of progesterone on Day 11 or 12 (Fig. 3), 4-5 days after the last TRH injection, and all gave birth on Day 33 or 34 (Fig. 3; Table 1). The intervals from the start of treatment to the progesterone peak and to birth were significantly longer in the TRH-treated females $(P<0.01$ and $P<0.02$ respectively; paired $t$ test) (Table 1$)$.

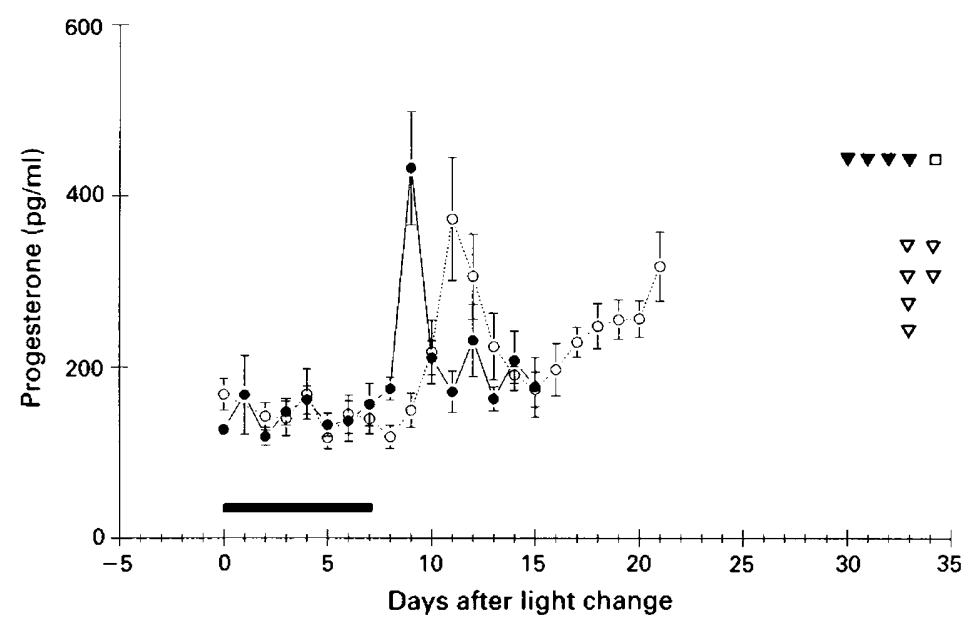

Fig. 3. Plasma progesterone profiles (mean \pm s.e.m.) showing early progesterone peaks for control females $(N=6)(\Theta)$ and TRH-treated females $(N=6)(O)$ in Exp. 1A. Solid line indicates period of treatment with TRH or saline vehicle; $\boldsymbol{\nabla}$, births; $\square$, oestrus for the control females; $\nabla$, births for TRH-treated females.

Experiment 1B: response to ovine prolactin. At $30 \mathrm{~min}$ after the injection of ovine prolactin, plasma prolactin concentrations were $>100 \mathrm{ng} / \mathrm{ml}$, but had declined to pre-injection levels within $2.5 \mathrm{~h}$. None of the saline-treated females showed any change in plasma prolactin concentrations (Fig. 4).

The 4 control females had early peaks of progesterone between Days 6 and 9 and gave birth 27-30 days after the change to the stimulatory photoregimen, 21 days after their early progesterone peak (Fig. 5; Table 1). The prolactin-treated females showed peaks of progesterone on Day 14 or 15 (Fig. 5), 5 or 6 days after the last injection of prolactin, and all gave birth on Day 36 or 37 . These intervals from the start of treatment were significantly delayed $(P<0.001$ and $P<0.003$ respectively, paired $t$ test) compared to the controls. However, as in the control females, the interval from the early progesterone peak to birth was 21 days (Fig. 5; Table 1). 
Table 1. Responses of control and treated females in Exps 1A and 1B, i.e. intervals (days) from light change to early progesterone peaks and birth, and the interval from the peak to birth

\begin{tabular}{|c|c|c|c|c|c|}
\hline & & \multirow[b]{2}{*}{$\begin{array}{l}\text { No. of } \\
\text { tammars }\end{array}$} & \multicolumn{2}{|c|}{ Light change to: } & \multirow[b]{2}{*}{$\begin{array}{l}\text { Progesterone } \\
\text { peak to birth }\end{array}$} \\
\hline \multicolumn{2}{|c|}{ Experiment } & & $\begin{array}{l}\text { Progesterone } \\
\text { peak }\end{array}$ & Birth & \\
\hline \multirow[t]{3}{*}{$1 \mathrm{~A}$} & Controls & 4 & $\begin{array}{c}8 \cdot 8 \pm 0 \cdot 5 \\
(8-10)\end{array}$ & $\begin{array}{c}31 \cdot 5 \pm 0 \cdot 6 \\
(30-33)\end{array}$ & $\begin{array}{c}22 \cdot 8 \pm 0 \cdot 6 \\
(21-24)\end{array}$ \\
\hline & TRH-treated & 6 & $\begin{array}{c}11 \cdot 5 \pm 0 \cdot 2 \\
(11-12)\end{array}$ & $\begin{array}{c}33 \cdot 3 \pm 0 \cdot 2 \\
(33-34)\end{array}$ & $\begin{array}{c}21 \cdot 8 \pm 0 \cdot 3 \\
(21-23)\end{array}$ \\
\hline & $\begin{array}{l}\text { Differences } \\
\text { Significance* }\end{array}$ & & $\begin{array}{l}+2.7 \text { days } \\
P<0.01\end{array}$ & $\begin{array}{l}+1.8 \text { days } \\
P<0.02\end{array}$ & $\begin{array}{l}-1 \text { day } \\
\text { NS }\end{array}$ \\
\hline \multirow[t]{4}{*}{$1 \mathrm{~B}$} & Controls & 4 & $\begin{array}{c}7 \cdot 0 \pm 0 \cdot 7 \\
(6-9)\end{array}$ & $\begin{array}{c}28 \cdot 3 \pm 0 \cdot 8 \\
(27-30)\end{array}$ & $\begin{array}{c}21 \cdot 3 \pm 0 \cdot 3 \\
(21-22)\end{array}$ \\
\hline & Prolactin-treated & 5 & $\begin{array}{c}14.9 \pm 0.3 \\
(14-15 \cdot 5)\end{array}$ & $\begin{array}{c}36 \cdot 4 \pm 0 \cdot 3 \\
(36-37)\end{array}$ & $\begin{array}{c}21 \cdot 3 \pm 0 \cdot 2 \\
(21-22)\end{array}$ \\
\hline & Differences & & +8 days & +8 days & 0 days \\
\hline & Significance* & & $P<0.001$ & $P<0.003$ & NS \\
\hline
\end{tabular}

Values are mean \pm s.e.m. with the range in parentheses.

*Paired $t$ tests.

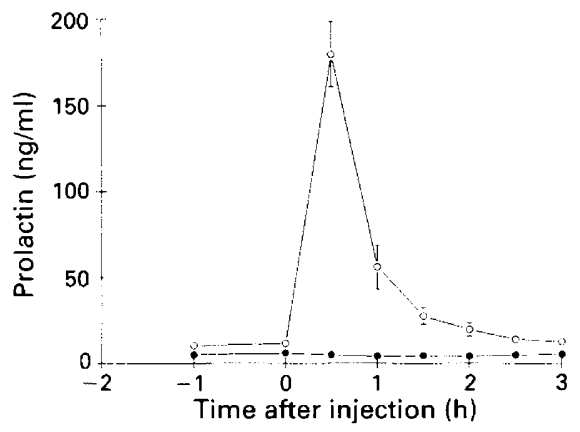

Fig. 4. Plasma prolactin concentrations (mean \pm s.e.m.) in tammars in Exp. 1B before and after intravenous injection with PBS $(N=4)(0)$ or exogenous ovine prolactin $(N=5)(O)$. Samples were taken on the last day of treatment (Day 9 after photoperiod change).

\section{Experiment 2: effect of abolishing the prolactin pulse in animals held on an inhibitory photoperiod}

Plasma prolactin. Morning plasma prolactin pulses were present in 7 of the 8 animals 3 days before the start of treatment with bromocriptine or saline vehicle. On the first day (Day 0 ) of treatment with bromocriptine 2 females showed a prolactin pulse before, and one after, the injection of bromocriptine. In the 4th animal no pulse was detected. Prolactin pulses were detected on Days 4 (the last day of treatment) and 7 in 2 females, but were absent in the remaining 2 animals on both days. Prolactin pulses were detected in all saline-treated animals $(\mathrm{N}=4)$ on at least 2 of the 3 days sampled (Days 0, 4 and/or 7).

Plasma progesterone. The 2 females which did not have a prolactin pulse after 5 consecutive days of treatment with bromocriptine reactivated; they had progesterone peaks on Day 6 or 7 and gave birth 22 days later, 28 and 29 days after start of treatment. The remaining 2 animals and the saline-treated females did not show any changes in progesterone profiles until after the lights were changed on Day 15; progesterone peaks were detected 5-12 days after the light change or 20-27 


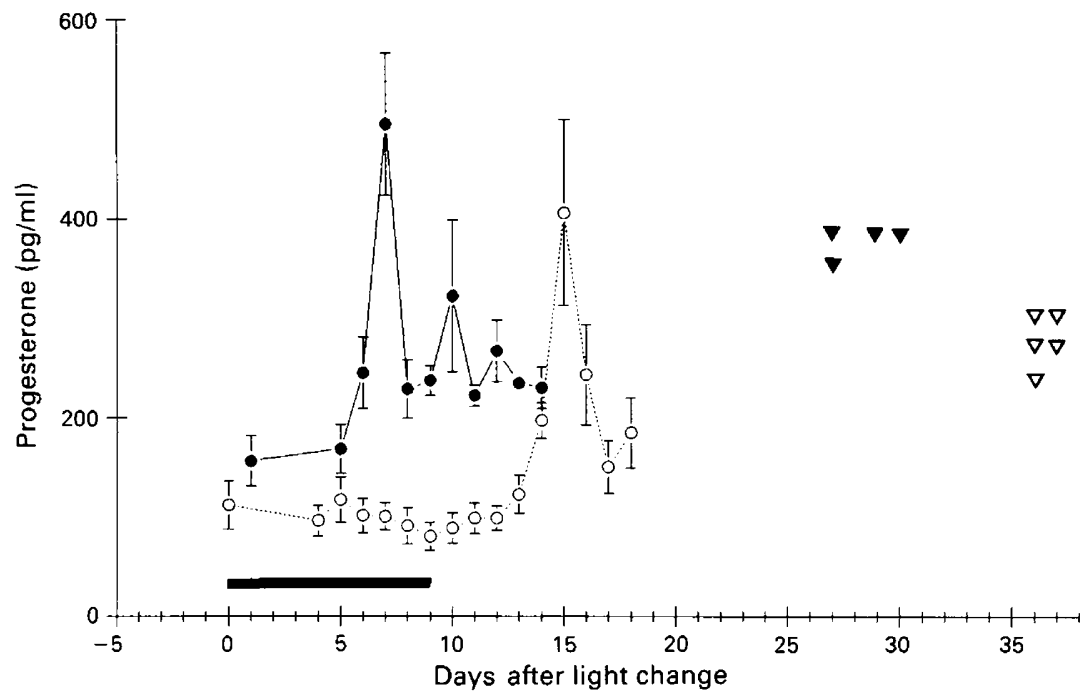

Fig. 5. Plasma progesterone profiles showing early progesterone peaks for control females $(\mathrm{N}=4)(\odot)$ and prolactin-treated females $(\mathrm{N}=5)(\mathrm{O})$ in Exp. 1B. Solid line indicates period of treatment with ovine prolactin or saline vehicle; $\nabla$, births in control females; $\nabla$, births in prolactin-treated females.

Table 2. Responses of individual females in Exp. 2 to treatment with bromocriptine or saline vehicle and subsequent light change from

15L:9D to $12 \mathrm{~L}: 12 \mathrm{D}$

\begin{tabular}{lcc}
\hline & \multicolumn{2}{c}{ Treatment } \\
\cline { 2 - 3 } & Bromocriptine & Control \\
\hline $\begin{array}{l}\text { Interval to progesterone } \\
\text { peak (days) }\end{array}$ & & \\
$\quad$ After treatment & $6,7,23,27$ & $20,22,23,24$ \\
$\quad$ After light change & $-,-, 8,12$ & $5,7,8,9$ \\
Interval to birth (days) & & \\
$\quad$ After treatment & $28,29,45,49$ & $41,[46]^{*}, 45,46$ \\
$\quad$ After light change & $13,14,30,34$ & $26,[31]^{*}, 30,31$ \\
Progesterone peak to birth & $22,22,22,22$ & $21,[24]^{*}, 22,22$ \\
\hline
\end{tabular}

*[ ] animal entered oestrus, no birth detected.

days from the start of treatment. Births occurred 26-34 days after the light change or 41-49 days after the initial treatment (Table 2).

\section{Discussion}

Many seasonally breeding mammals, for example the sheep, show marked elevations of plasma prolactin throughout the non-breeding season (Walton et al., 1977), and these concentrations change in response to administered melatonin (Symons et al., 1983). Prolactin does not appear directly to influence ovarian function in the ewe during anoestrus; rather, melatonin is the mediator of photoperiod-dependent effects on the hypothalamic GnRH pulse generator (see Karsch et al., 1984; Arendt, 1986). In the tammar, in contrast, there is no change in basal LH secretion (Tyndale- 
Biscoe \& Hearn, 1981; Tyndale-Biscoe et al., 1986) or in the sensitivity of the hypothalamus to steroid feedback (Horn et al., 1985) throughout the annual cycle but melatonin and prolactin play a central role in the control of seasonal quiescence.

Tyndale-Biscoe \& Hawkins (1977) demonstrated that prolactin is the pituitary inhibitory factor which maintains the tammar CL in quiescence, and, when elevated concentrations of plasma prolactin were found during seasonal quiescence (Tyndale-Biscoe \& Hinds, 1984) and in animals held in summer solsticial photoperiods (Hinds \& den Ottolander, 1983), it was proposed that hyperprolactinaemia may be important in the regulation of seasonal breeding in the tammar. However, in another study no seasonal changes in prolactin were observed between October and February (McConnell \& Hinds, 1985), and the significance of elevated prolactin concentrations was questioned (Curlewis et al., 1986). The present study resolves this uncertainty. The most critical factor for the maintenance of quiescence in the tammar is not sustained high concentrations of prolactin but the occurrence of a transient prolactin pulse; daily intravenous injections of ovine prolactin, which were cleared from the circulation within $2 \mathrm{~h}$ of treatment, maintained quiescence in tammars experiencing a stimulatory photoperiod. On re-examination, the results of the earlier studies are consistent with the findings of the present study. Because the daily blood samples were always collected in the morning within $1-2 \mathrm{~h}$ of lights on in the study of Hinds \& den Ottolander (1983), it is probable that the morning prolactin pulse was being detected during the inhibitory photoperiods, as well as its loss after the change to a stimulatory photoperiod. Similarly, although the timing of the prolactin pulse in animals held under natural lighting conditions has not been determined, in the study of Tyndale-Biscoe \& Hinds (1984) the animals were also sampled within 2-3 h of dawn. In the third study (McConnell \& Hinds, 1985), in contrast, in which no changes in prolactin concentrations were observed, the blood samples were collected 3-5 h after dawn, after the prolactin pulse would have subsided.

Not only did exogenous prolactin maintain quiescence but an endogenous pulse induced by TRH achieved the same result. In both Exp. IA (TRH treatment) and Exp. IB (exogenous prolactin) the differences between the treated and control groups in the time to the progesterone peak and to birth were significant. However, in both cases, the differences between the control and treated animals were less than the duration of the treatments. Tyndale-Biscoe et al. (1986) showed that it takes 3 days for a change in photoperiod to be translated via the pineal gland to the pituitary gland and then to the ovaries. In the TRH-treated and prolactin-treated animals the photoperiod signal would have been processed after the light change, as in the control females, but the last factor, the endogenous prolactin pulse, would have been maintained by injection of TRH or prolactin. Hence once treatment ceased, the response time of the CL was shortened by the time between photoperiod change and the abolition of the prolactin peak, and was similar to that after removal of pouch young (Hinds \& Tyndale-Biscoe, 1982a), and the progesterone pulse occurred 4-6 days after the end of treatment.

McConnell et al. (1986) found that the prolactin pulse was absent by the 5 th day after a stimulatory photoperiod change. In this study, the prolactin pulse was absent in 5 of 6 control females (Exp. 1A) between the 3rd and 4th days after the light change. The interval to the progesterone peak after the prolactin pulse was lost was 4-6 days in all females, similar to the interval after removal of pouch young (Hinds \& Tyndale-Biscoe, 1982a). This response by the pituitary confirms the earlier observations (Tyndale-Biscoe et al., 1986) that the melatonin-mediated message is transduced by the pituitary within 3 days.

Exogenous intramuscular injections of prolactin for 9 consecutive days also delayed reactivation in female Bennett's wallabies held in stimulatory photoperiods (Brinklow \& Loudon, 1989), and the time to the early progesterone peak after the end of treatment was the same as after removal of pouch young. However, each intramuscular injection resulted in elevated concentrations of prolactin for up to $24 \mathrm{~h}$, and so it is not clear whether daily intravenous injections resulting in elevated prolactin for only a short period would have the same effect as in the tammars. No early morning prolactin pulse has been reported for the Bennett's wallaby (Curlewis \& Loudon, 1988). 
The response of the tammars to bromocriptine treatment was similar to that observed under natural conditions at the same time of year (August-September) by Tyndale-Biscoe et al. (1986). Half of the tammars treated with bromocriptine for 5 consecutive days lost their morning prolactin pulse and showed reactivated $\mathrm{CL}$. The interval to birth, however, was $2-3$ days longer than during lactational quiescence, in which births occur 26-27 days after a single injection of bromocriptine (Tyndale-Biscoe \& Hinds, 1984), or after removal of pouch young (26-27 days; Merchant, 1979), which suggests that during seasonal quiescence the prolactin pulse must be absent for at least $2-3$ days before reactivation is induced. Previous studies were unable to demonstrate an effect of bromocriptine on basal plasma prolactin concentrations and it was suggested that the dopamine agonist may be directly affecting the CL and not the hypothalamus/pituitary (Tyndale-Biscoe \& Hinds, 1984). In the present study, the morning prolactin pulse was abolished in 2 of 4 animals after bromocriptine treatment and only these responded, which suggests that the drug is, in fact, acting at the level of the pituitary, and so the dopaminergic control system may be operative. Nevertheless, the animals are not as responsive as in lactational quiescence, either in terms of the number responding ( 2 of 4 animals) or in the time taken to reactivate after start of treatment (Tyndale-Biscoe \& Hinds, 1984; Tyndale-Biscoe et al., 1986).

Bennett's wallabies experiencing natural photoperiod just before the summer solstice and treated with bromocriptine (time not specified in relation to dawn) did not reactivate, on the basis of progesterone profiles, in the 11 days after start of treatment (Brinklow \& Loudon, 1989). It is not stated whether animals were checked subsequently for births. Tammars treated at the summer solstice also did not respond to bromocriptine but reactivated spontaneously a few days later in response to natural photoperiod changes (Tyndale-Biscoe \& Hinds, 1984). When the same group was treated again in February all responded to bromocriptine. Clearly there are seasonal differences in the response to bromocriptine which may reflect changes in the sensitivity of the dopaminergic system.

In the tammar, during lactational and seasonal quiescence, exposure to a $15 \mathrm{~L}: 9 \mathrm{D}$ or a $18 \mathrm{~L}: 6 \mathrm{D}$ photoregimen maintains the inhibition of the $\mathrm{CL}$, while reduction of the daylength to $12 \mathrm{~L}: 12 \mathrm{D}$ is stimulatory. Moreover, the response of the tammars to a stimulatory light change in March, August and October was identical; the interval to the progesterone peak, the interval from the progesterone peak to birth, or the time to birth were not significantly different (compare results for controls in Tables 1 and 2).

The results of this study clearly demonstrate that the presence of the early morning pulse of prolactin in the female tammar during seasonal quiescence is essential for maintenance of the inhibition of the CL. The abolition of the pulse is the critical event which must occur before the CL is reactivated.

I thank John Wright for assistance with blood sampling and assays; Dr W. Mueller for statistical advice; and Dr C. H. Tyndale-Biscoe and Dr P. A. Janssens for helpful discussion during the study and valuable criticism of the manuscript.

\section{References}

Arendt, J. (1986) Role of the pineal gland and melatonin in seasonal reproductive function in mammals. Oxford Rev. Reprod. Biol. 8, 266-320.

Brinklow, B.R. \& Loudon, A.S.I. (1989) Effect of exogenous prolactin and bromocriptine on seasonal reproductive quiescence in the Bennett's wallaby. (Macropus rufogriseus rufogriseus). J. Endocr. 120, 189-193.

Curlewis, J.D. \& Loudon, A.S.I. (1988) Experimental manipulations of prolactin following removal of pouch young or bromocriptine treatment during lactational quiescence in the Bennett's wallaby. $J$. Endocr. 119, 405-411.

Curlewis, J.D., White, A.S., Loudon, A.S.I. \& McNeilly, A.S. (1986) Effects of lactation and season on plasma prolactin concentrations and response to bromocriptine during lactation in the Bennett's wallaby (Macropus rufogriseus rufogriseus). J. Endocr. 110, 59-66.

Hearn, J.P. (1974) The pituitary gland and implantation in the tammar wallaby, Macropus eugenii. J. Reprod. Fert. 39, 235-241. 
Hinds, L.A. \& den Ottolander, R. (1983) Effect of changing photoperiod on peripheral plasma prolactin and progesterone concentrations in the tammar wallaby (Macropus eugenii). J. Reprod. Fert. 69, 631-639.

Hinds, L.A. \& Tyndale-Biscoe, C.H. (1982a) Plasma progesterone levels in the pregnant and non-pregnant tammar, Macropus eugenii. J. Endocr. 93, 99-107.

Hinds, L.A. \& Tyndale-Biscoe, C.H. (1982b) Prolactin in the marsupial Macropus eugenii, during the estrous cycle, pregnancy and lactation. Biol. Reprod. 26, 391-398.

Horn, C.A., Fletcher, T.P. \& Carpenter, S. (1985) Effects of oestradiol-17ß on peripheral plasma concentrations of LH and FSH in ovariectomized tammars (Macropus eugenii). J. Reprod. Fert. 73, 585-592.

Karsch, F.J., Bittman, E.L., Foster, D.L., Goodman, R.L., Legan, S.J. \& Robinson, J.E. (1984) Neuroendocrine basis of seasonal reproduction. Recent Prog. Horm. Res, 40, 185-232.

Loudon, A.S.I. \& Curlewis, J.D. (1987) Refractoriness to melatonin and short daylengths in early seasonal quiescence in the Bennett's wallaby (Macropus rufogriseus rufogriseus). J. Reprod. Fert. 81, 543-552.

McConnell, S.J. \& Hinds, L.A. (1985) Effect of pinealectomy on plasma melatonin, prolactin and progesterone concentrations during seasonal reproductive quiescence in the tammar, Macropus eugenii. $J$. Reprod. Fert. 75, 433-440.

McConnell, S.J. \& Tyndale-Biscoe, C.H. (1985) Response to photoperiod in peripheral plasma melatonin and the effects of exogenous melatonin on seasonal quiescence in the tammar, Macropus eugenii. J. Reprod. Fert. 73, 529-538.

MeConnell, S.J., Tyndale-Biscoe, C.H. \& Hinds, L.A. (1986) Change in duration of elevated concentrations of melatonin is the major factor in photoperiod response of the tammar, Macropus eugenii. J. Reprod. Fert. 77, 623-632.

Merchant, J.C. (1979) The effect of pregnancy on the interval between one oestrus and the next in the tammar wallaby, Macropus eugenii. J. Reprod. Fert. 56, 459-463.

Merchant, J.C. \& Calaby, J.H. (1981) Reproductive biology of the red necked wallaby (Macropus rufogriseus banksianus) and Bennett's wallaby (M. $r$. rufogriseus) in captivity. J. Zool., Lond. 194, 203-217.
Neill, J.D. \& Reichert, L.E., Jr (1971) Development of a radioimmunoassay for rat prolactin and evaluation in the NIAMD rat prolactin radioimmunoassay. Endocrinology 88, 548-555.

Sadleir, R.M.F.S. \& Tyndale-Biscoe, C.H. (1977) Photoperiod and the termination of embryonic diapause in the marsupial Macropus eugenii. Biol. Reprod. 16, 605-608.

Sernia, C., Hinds, L.A. \& Tyndale-Biscoe, C.H. (1980) Progesterone metabolism during embryonic diapause in the tammar wallaby, Macropus eugenii. $J$. Reprod. Fert. 60, 139-147.

Stewart, F. (1984) Mammogenesis and changing prolactin receptor concentrations in the mammary glands of the tammar wallaby (Macropus eugenii). $J$. Reprod. Fert. 71, 141--148.

Symons, A.M., Arendt, J. \& Laud, C.A. (1983) Melatonin feeding decreases prolactin levels in the ewe. $J$. Endocr. 99, 41-46.

Tyndale-Biscoe, C.H. \& Hawkins, J. (1977) The corpora lutea of marsupials: aspects of function and control. In Reproduction and Evolution, pp. 245-252. Eds J. H. Calaby \& C. H. Tyndale-Biscoe. Australian Academy of Science, Canberra.

Tyndale-Biscoe, C.H. \& Hearn, J.P. (1981) Pituitary and ovarian factors associated with seasonal quiescence of the tammar wallaby, Macropus eugenii. J. Reprod. Fert. 63, 225-230.

Tyndale-Biscoe, C.H. \& Hinds, L.A. (1984) Seasonal patterns of circulating progesterone and prolactin and response to bromocriptine in the female tammar, Macropus eugenii. Gen. comp. Endocr. 53, 58-68.

Tyndale-Biscoe, C.H. \& Renfree, M.B. (1987) Reproductive Physiology of Marsupials. Cambridge University Press.

Tyndale-Biscoe, C.H., Hinds, L.A. \& McConnell, S.J. (1986) Seasonal breeding in a marsupial: opportunities of a new species for an old problem. Recent Prog. Horm. Res. 42, 471-512.

Walton, J.S., McNeilly, J.R., McNeilly, A.S. \& Cunningham, F.J. (1977) Changes in concentrations of follicle-stimulating hormone, luteinizing hormone, prolactin and progesterone in plasma of ewes during the transition from anoestrus to breeding activity. $J$. Endocr. 75, 127-136.

Received 15 March 1989 